\title{
Desoneração previdenciária e o comportamento dos custos das empresas de calçados listadas na BM\&FBOVESPA
}

Rúbia Albers Magalhães
Mestrado em andamento em Contabilidade pela Universidade Federal de Santa Catarina - UFSC Campus Reitor João David Ferreira Lima, s/n. Trindade. Florianópolis/SC. CEP: 88.040-900 E-mail: rubia@contexata.com.br

Thayse Moraes Elias Mestrado em andamento em Contabilidade pela Universidade Federal de Santa Catarina - UFSC Campus Reitor João David Ferreira Lima, s/n. Trindade. Florianópolis/SC. CEP: 88.040900 E-mail: thaysemooraes@hotmail.com

Luiz Felipe Ferreira Doutorado em Engenharia Ambiental pela Universidade Federal de Santa Catarina UFSC Professor da Universidade Federal de Santa Catarina - UFSC Campus Reitor João David Ferreira Lima, s/n. Trindade. Florianópolis/SC. CEP: 88.040900 E-mail: luiz.felipe@ufsc.br Altair Borgert
Doutorado em Engenharia de Produção pela Universidade Federal de Santa Catarina -
UFSC
Professor da Universidade Federal de Santa Catarina - UFSC
Campus Reitor João David Ferreira Lima, s/n. Trindade. Florianópolis/SC. CEP: $88.040-$
900
E-mail: altair@borgert.com.br

\section{RESUMO}

A desoneração da folha de pagamento é constituída pela substituição da Contribuição Previdenciária Patronal - CPP incidente sobre a folha de salários com a alíquota de $20 \%$, pela Contribuição Patronal sobre a Receita Bruta - CPRB, que consiste na aplicação de uma alíquota sobre o valor da receita bruta, conforme o setor de atividade econômica da empresa. Neste contexto, este estudo tem como objetivo identificar o comportamento dos custos das empresas do segmento de calçados que estão listadas na BM\&FBOVESPA no período de 2007 a 2016, que compreende momentos antes e após a desoneração da folha de pagamento. As análises abrangem a estatística 
Desoneração previdenciária e o comportamento dos custos das empresas de calçados listadas na

BM\&FBOVESPA

Rúbia Albers Magalhães, Thayse Moraes Elias, Luiz Felipe Ferreira, Altair Borgert

descritiva e a tendência linear. Além destas, o Teste $t$ de Student é utilizado para verificar a existência de diferenças de médias das variáveis antes e após a desoneração. Os resultados encontrados, com base nas hipóteses admitidas, apontam que os gastos com pessoal, os custos dos produtos vendidos, as despesas com vendas e administrativas, os custos totais e a margem de lucro não se alteraram com as medidas de desoneração da folha de pagamento.

Palavras-chave: Desoneração Previdenciária. Custos. Setor de Calçados.

\section{Payroll tax exemption and cost behavior in footwear manufacturers listed on the São Paulo stock exchange}

\section{ABSTRACT}

Payroll tax exemption is the substitution of Employer Pension Contributions - CPP, at the Sovereign Employer Contribution of Gross Revenue - CPRB, in accordance with a company's industry, which consists of the Application a rate on the Gross Revenue value, in place of social security contributions deducted from payroll, at a rate of $20 \%$. This study seeks to identify cost behaviors in footwear manufacturing companies listed on the São Paulo Stock Exchange between 2007 and 2016, spanning intervals both before and after in the implementation of payroll tax exemption. The analysis employed are the descriptive statistical and the linear trend, further, Student's t-test is utilized to verify the existence of a difference of means in the periods prior and subsequent to the exemption. Drawing from the results obtained and based off of the hypotheses posed herein, personnel costs, cost of goods sold, selling and administrative expenses, total costs and profit margin are not affected by the implementation of payroll tax exemption.

Keywords: Pension contributions. Costs. Footwear industry.

\section{INTRODUÇÃO}

O Brasil tem uma das mais altas cargas tributárias do mundo e, segundo aponta o Instituto Brasileiro de Planejamento Tributário (Instituto Brasileiro de Planejamento Tributário, 2015), subiu pelo segundo ano consecutivo e representou $35,42 \%$ do Produto Interno Bruto (PIB) em 2014, ante um percentual de 35,04\% em 2013. Dentre os tributos pagos, os encargos sociais do Fundo de Garantia por Tempo de Serviços (FGTS) e a contribuição ao Instituto Nacional do Seguro Social (INSS), recolhidos sobre 
a folha de pagamento, representaram $8,69 \%$ do PIB em 2012, além do valor pago como Contribuição Previdenciária Patronal (Crepaldi, 2012).

Os encargos trabalhistas representam cerca de $35 \%$ da folha de pagamento, sendo a contribuição previdenciária o tributo de maior peso, e o impacto dessa carga tributária sobre a folha de pagamento recai totalmente sobre a empresa. Tal fato, muitas vezes, inviabiliza a contratação de novos empregados e impede as empresas brasileiras de competir com as empresas estrangeiras (Cintra, 2010).

A fim de reduzir os custos do trabalho para, entre outros objetivos, aumentar o nível de emprego, o Governo Federal sancionou a Medida Provisória no 540/2011, convertida na Lei ํo 12.546/2011 e suas alterações, que substitui a Contribuição Previdenciária Patronal - CPP de $20 \%$ sobre a folha de pagamento de algumas atividades econômicas, pela nova Contribuição Previdenciária sobre a Receita Bruta CPRB, mediante a aplicação das alíquotas de $1 \%$ a $2 \%$, de acordo com a atividade econômica. Vale destacar que, a partir de 01/12/2015, por força da Lei 13.161/2015, a aplicação da desoneração é facultativa.

Para Cintra (2010), a proposta de desoneração previdenciária da folha de pagamento das empresas, mediante a alteração das alíquotas das contribuições patronais, reduzirá os custos tributários incidentes sobre o trabalho, de modo a abrir espaços para a redução dos custos de produção e aumentar a competitividade dos produtos brasileiros diante dos concorrentes estrangeiros.

De acordo com pesquisas já realizadas por Fregulia (2013), Eckert, Biasio, Mecca e Turella (2013), Santos, Freitas, Tomasi, Pietrobelli e Dutra (2013), Oliveira, Petri, Casagrande e Rosa (2014), Uszacki e Silva (2014), Echevarrieta, Magalhães, Casagrande e Rosa (2015), Neves, Fernandes e Barreto (2016), Ludwig, Borgert e Kremer (2016), Barth, Souza e Oliveira (2016), houve redução no valor recolhido dos encargos da folha de pagamento em empresas dos setores de construção civil, indústria de vidros, plásticos, moveleiro, metalúrgico, hoteleiro, construção de obras de infraestrutura, construção civil e transporte rodoviário coletivo de passageiros 
respectivamente, ou seja, o objetivo de reduzir os custos laborais, proposto pelo Plano Brasil Maior, foi alcançado nas empresas destes setores.

A indústria de calçados foi um dos primeiros setores a serem contemplados pela desoneração da folha de pagamento, com a alíquota de 1,5\% sobre a receita bruta interna e com vigência de 01/12/2011 a 31/07/2012 (Brasil, 2011a). Posteriormente, houve alteração da alíquota, a partir de $01 / 08 / 2012$, para 1,0\% sobre a receita bruta interna (Brasil, 2012) e, a partir de 01/12/2015, para 1,5\% (Brasil, 2015a).

$\mathrm{O}$ presente estudo desenvolve-se em empresas calçadistas ao considerar que 0 Brasil é o terceiro maior produtor mundial neste segmento, atrás apenas da China e da Índia. Em 2016, foi responsável por empregar 3,6\% da força de trabalho do país e produziu cerca de 944 milhões de pares de calçados. Exportou 126 milhões de pares de calçados e gerou US\$999 milhões com as exportações. O parque calçadista brasileiro é formado por mais de 7,7 mil empresas e emprega diretamente 300 mil pessoas (Abicalçados, 2016).

Neste sentido, a pergunta que orienta a presente pesquisa é a seguinte: $A$ desoneração da folha de pagamento impactou nos custos, despesas e margem de lucro das empresas de calçados listadas na BM\&FBOVESPA?

Com o intuito de responder tal indagação, o objetivo da pesquisa consiste em identificar e analisar o comportamento dos custos, despesas e margem de lucro das empresas do segmento de calçados listadas na BM\&FBOVESPA durante o período de 2007 a 2016.

A justificativa deste estudo está relacionada ao fato de representar o aprofundamento do conhecimento acerca da medida governamental e a aproximação entre a teoria e a prática, ao compreender o comportamento dos custos de empresas antes e depois da desoneração da folha de pagamento. Relaciona-se, ainda, aos gestores, profissionais contábeis e usuários internos que devem constantemente avaliar os impactos ocorridos nos custos para melhorar os resultados econômicos. A pesquisa pretende também contribuir para a academia, uma vez que questões de alterações da legislação e carga tributária são abordadas. 
Desoneração previdenciária e o comportamento dos custos das empresas de calçados listadas na

BM\&FBOVESPA

Rúbia Albers Magalhães, Thayse Moraes Elias, Luiz Felipe Ferreira, Altair Borgert

\section{REVISÃO DA LITERATURA}

Nesta etapa do estudo, reúnem-se informações necessárias ao entendimento da desoneração da folha de pagamento, para auxiliar a compreensão do assunto. Além disto, apresentam-se estudos anteriores que buscaram avaliar o efeito desta medida nas empresas.

\subsection{Contribuição Previdenciária}

A Secretaria da Receita Federal do Brasil (RFB) aponta que o sistema previdenciário brasileiro já passou por várias mudanças conceituais e estruturais, que envolvem o grau de cobertura, o elenco de benefícios oferecidos e a forma de financiamento do sistema. O primeiro registro dessa evolução no sistema previdenciário ocorreu no ano de 1888, por meio do Decreto $\mathrm{n}^{0}$ 9.912-A, que regulou o direito à aposentadoria dos empregados dos Correios, o qual fixou em 30 anos de efetivo serviço e idade mínima de 60 anos os requisitos para a aposentadoria. Em janeiro de 1919, por meio da Lei no 3.724, foi estabelecido o seguro contra acidentes de trabalho, ao tornar obrigatória a indenização, por parte do empregador, dos acidentes ocorridos na execução do trabalho (Receita Federal, 2016).

O conceito de previdência apareceu, pela primeira vez no Brasil, em 1923, com a criação da Lei Eloy Chaves (Decreto-Lei no 4.682, de 24 de janeiro de 1923), considerada como marco inicial do sistema previdenciário. Esta lei determinou a criação de uma Caixa de Aposentadoria e Pensões para empregados de empresas ferroviárias existentes na época. Cada empresa possuía uma caixa destinada a amparar seus empregados na inatividade, a fim de assegurar os benefícios de aposentadoria por invalidez, aposentadoria ordinária (equivalente à atual aposentadoria por tempo de contribuição), pensão por morte e assistência médica. No decorrer das décadas de 1920 e 1930, o sistema foi estendido a empresas de diversas categorias profissionais, e chegaram a existir 183 caixas em 1937. 
A partir de 1930, foi criado o Ministério do Trabalho, Indústria e Comércio, e a previdência social passou a merecer maior atenção por parte do governo. Começou então uma nova fase, na qual foram criados os institutos de aposentadorias e pensões, e a cobertura previdenciária foi estendida à totalidade dos trabalhadores urbanos e a boa parte dos autônomos.

Em 1ํ de maio de 1943, foi aprovado o Decreto-Lei ํo 5.452, a Consolidação das Leis do Trabalho, elaborada pelo Ministério do Trabalho, Indústria e Comércio, que elaborou também o primeiro projeto de Consolidação das Leis de Previdência Social. Dois anos depois, foi criado o Instituto de Serviços Sociais do Brasil, órgão que unificaria as instituições previdenciárias existentes e centralizaria o seguro social de toda a população ativa.

Após 14 anos, foi promulgada a Lei Orgânica da Previdência Social (LOPS), em 26 de agosto de 1960, que uniformizou as contribuições e os planos de benefícios dos diversos institutos. E, em 1977, foi criado o Sistema Nacional de Previdência e Assistência Social, o qual possuía o escopo de propor a política de previdência e assistência médica, farmacêutica e social, para todas as pessoas que exercem atividade remunerada, inclusive trabalhadores domésticos e rurais.

A partir daí, com a promulgação da Constituição Federal de 1988, foram assegurados os direitos relativos à saúde, à previdência e à assistência social, ao determinar um conjunto integrado de ações de iniciativa dos poderes públicos e da sociedade, que compreende a seguridade social, cujo financiamento é definido pelo artigo 195, que se lê:

Art. 195. A seguridade social será financiada por toda a sociedade, de forma direta e indireta, nos termos da lei, mediante recursos provenientes dos orçamentos da União, dos Estados, do Distrito Federal e dos Municípios, e das seguintes contribuições sociais: I - do empregador, da empresa e da entidade a ela equiparada na forma da lei, incidentes sobre: a) a folha de salários e demais rendimentos do trabalho pagos ou creditados, a qualquer título, à pessoa física que lhe preste serviço, mesmo sem vínculo empregatício (Brasil, 1988). 
Alicerçada nessa previsão constitucional, a Lei oㅜ 8.212, de 24 de julho de 1991, dispõe sobre a organização da seguridade social e institui o Plano de Custeio da Seguridade Social. No seu art. ํㅡㄹㅡ 22, define que a seguridade social é financiada por toda a sociedade, em especial as empresas, que devem recolher a contribuição previdenciária de $20 \%$ sobre as remunerações pagas em folha de pagamento mensal, cujo resultado é destinado à Previdência Social e sua arrecadação administrada pela Secretaria da Receita Federal do Brasil, conforme regulamentado pela Instrução Normativa RFB no 971, de 13 de novembro de 2009.

No contexto da crise financeira internacional de 2008 e do Plano Brasil Maior, foi editada a Medida Provisória ํㅡ 540, de 02 de agosto de 2011, que visa incentivar a competitividade das empresas, ao estimular a formalidade do mercado de trabalho, reduzir os custos laborais e instituir, assim, a "Desoneração da Folha de Pagamento" (Plano Brasil Maior, 2011). Essa medida foi operacionalizada pela criação da Contribuição Patronal sobre a Receita Bruta, que consiste na aplicação de uma alíquota sobre o valor da receita bruta das empresas, em substituição à regra geral da Lei № 8.212/1991, que trata da contribuição sobre os salários.

Esse benefício fiscal tinha caráter temporário e vigeria até 31 de dezembro de 2012. Porém a MP no 540/11 foi convertida na Lei 12.546, de 14 de dezembro de 2011, já com algumas modificações: sua vigência foi estendida até 31 de dezembro de 2014; novos produtos foram incluídos e alguns foram excluídos. Essa mudança atinge 56 setores da economia (Brasil, 2011).

A Lei $n^{0}$ 12.546/2011 esclarece que a nova contribuição patronal sobre a receita bruta substitui somente a contribuição previdenciária patronal de $20 \%$ sobre a folha de pagamento para as atividades contempladas pela legislação, mas não substitui as demais contribuições incidentes sobre a folha de pagamento como o Grau de Incidência de Incapacidade Laborativa Decorrente de Riscos Ambientais de Trabalho - GIIL RAT e a contribuição destinada a outras entidades e fundos (terceiros).

Em 31 de agosto de 2016, foi realizada uma nova alteração, motivada pela necessidade de aumentar a arrecadação, no contexto do ajuste fiscal, para 
recuperação das contas públicas (Receita Federal, 2015). A Lei № 13.161, de 31 de agosto de 2015, contempla facultatividade do regime da desoneração da folha de pagamento e aumenta as alíquotas da CPRB de duas para seis alíquotas, que passaram a vigorar em $1^{\circ}$ de dezembro de 2015.

Com relação ao cálculo da contribuição, devem ser excluídas a receita bruta originada de exportação, as vendas canceladas, os descontos incondicionais concedidos e os impostos incluídos na receita bruta (Brasil, 2015c). Com o propósito de esclarecer a aplicação da Lei no 8.212/1991 (medida aplicada antes da desoneração), apresenta-se uma simulação do cálculo da Contribuição Previdenciária Patronal a partir da média dos gastos com pessoal e da receita bruta das empresas objeto da pesquisa, conforme Tabela 1.

Tabela 1

Cálculo da Contribuição Previdenciária Patronal (Lei no 8.212/1991)

\begin{tabular}{lrr}
\hline Total da remuneração da folha de pagamento & $\mathbf{R} \mathbf{2 7 0 . 0 0 0 , 0 0}$ \\
\hline CPP $(20 \%)$ & $\mathrm{R} \$$ & $54.000,00$ \\
GIIL RAT (3\%) & $\mathrm{R} \$$ & $8.100,00$ \\
Terceiros (5,8\%) & $\mathrm{R} \$$ & $15.660,00$ \\
\hline Custo da Contribuição Previdenciária Patronal & $\mathrm{R} \$$ & $77.760,00$ \\
\hline
\end{tabular}

Nota. Fonte: Elaborada pelos autores, com base nos dados da pesquisa

A partir da desoneração, os cálculos da apuração da contribuição previdenciária no setor calçadista passaram a aplicar a alíquota de $1 \%$ sobre a receita bruta. $\mathrm{Na}$ Tabela 2, apresenta-se um exemplo do novo cálculo, com os mesmos dados considerados no exemplo anterior. 
Desoneração previdenciária e o comportamento dos custos das empresas de calçados listadas na

BM\&FBOVESPA

Rúbia Albers Magalhães, Thayse Moraes Elias, Luiz Felipe Ferreira, Altair Borgert

Tabela 2

Cálculo da Contribuição Patronal sobre a Receita Bruta (Lei no 12.546/2011)

\begin{tabular}{lrr}
\hline Receita Bruta da empresa & \multicolumn{2}{c}{$\mathbf{R} \mathbf{1 . 7 0 0 . 0 0 0 , 0 0}$} \\
Total da remuneração da folha de pagamento & $\mathbf{R} \$$ & $\mathbf{2 7 0 . 0 0 0 , 0 0}$ \\
\hline CPRB (1\%) & $\mathrm{R} \$$ & $17.000,00$ \\
GIIL RAT (3\%) & $\mathrm{R} \$$ & $8.100,00$ \\
Terceiros (5,8\%) & $\mathrm{R} \$$ & $15.660,00$ \\
\hline Custo da Contribuição Patronal & $\mathrm{R} \$$ & $40.760,00$ \\
\hline
\end{tabular}

Nota. Fonte: Elaborada pelos autores, com base nos dados da pesquisa

Com base nos exemplos simulados nas Tabelas 1 e 2, pode-se comparar e verificar que, no período anterior à desoneração da folha de pagamento, a Contribuição Previdenciária Patronal devida era de $\mathrm{R} \$ 77.760,00$ e, a partir da vigência da desoneração, os valores da Contribuição Patronal sobre a Receita Bruta passaram para $\mathrm{R} \$ 40.760,00$, o que gera economia tributária de $\mathrm{R} \$ 37.000,00$ no ano e representa uma redução nos custos empresariais.

A Receita Federal do Brasil evidencia o quanto deixou de arrecadar, em virtude da desoneração previdenciária patronal, em seus relatórios de acompanhamento realizados mensalmente. No setor da indústria calçadista, por exemplo, as estimativas de renúncia foram de $R \$ 1,45$ milhões, no período de janeiro de 2012 a março de 2015, conforme a Secretaria da Receita Federal (Brasil, 2015c).

A proposta de desoneração previdenciária da folha de pagamento das empresas, mediante a alteração das alíquotas das contribuições patronais, reduzirá os custos tributários incidentes sobre o trabalho, de modo a permitir a redução dos custos de produção e aumentar a competitividade dos produtos brasileiros diante dos concorrentes estrangeiros (Cintra, 2010).

\subsection{Estudos Anteriores}

A fim de verificar os subsídios que a desoneração da folha de pagamento acarretou a uma empresa de construção civil, Fregulia (2013) encontrou redução do custo com encargos; portanto, concluiu que a medida foi favorável à empresa 
analisada. Também com base em estudo de caso, Eckert et al. (2013) identificaram o impacto da medida no custo dos produtos em uma indústria de vidros e analisaram a influência no preço de venda. Como resultados, constataram um ganho com a desoneração da folha de pagamento, a consequente redução dos custos dos produtos e a reavaliação no preço de venda.

Santos et al. (2013) examinaram o impacto financeiro da desoneração em seis empresas do segmento de plástico e verificaram vantagem financeira para todas as empresas analisadas, com a mudança na forma de tributação. Não obstante, Oliveira et al. (2014) avaliaram o impacto da mudança na forma de cálculo da Contribuição Previdenciária Patronal em empresas do setor moveleiro e constataram uma redução do valor recolhido a título de tributos para o governo.

Ferrari, Kremer e Silva (2014) analisaram o comportamento dos custos das empresas do estado de Santa Catarina do segmento de fios e tecidos, listadas na BM\&FBOVESPA, antes e após a desoneração da folha de pagamento. As análises basearam-se em hipóteses de pesquisa em que se pressupõe que o desempenho do segmento após a desoneração é superior ao verificado no período anterior à medida. Como resultados, encontraram alterações nos custos dos produtos vendidos e nos custos totais das empresas analisadas.

Bertini e Wünsch (2014) identificaram o impacto da medida nas indústrias calçadistas do Vale do Paranhana e concluíram que houve redução dos custos, além do positivo impacto financeiro e contábil. Com análise voltada à empresa metalúrgica, Uszacki e Silva (2014) verificaram que o novo método de cálculo foi vantajoso e acarretou implicações positivas, uma vez que os resultados, após a medida, foram favoráveis, devido à redução nos custos.

No estudo de caso de Echevarrieta et al. (2015), foi demonstrada redução nos custos laborais em função da desoneração da folha de pagamento em um hotel, bem como o crescimento de $10 \%$ no número de empregados e o fortalecimento do mercado interno. Neves et al. (2016) verificaram que a medida empreendida pelo governo federal 
foi favorável, ou seja, desonerou os custos previdenciários, e o setor de construção de obras de infraestrutura obteve resultados vantajosos.

Em consonância com estes estudos, na pesquisa de Ludwig et al. (2016), os resultados evidenciaram que a empresa analisada do segmento de construção civil, que utiliza mão de obra própria, obteve benefícios com a alteração da legislação. Entre os benefícios, identificaram a redução do valor pago à previdência, enquanto que, na empresa que detém mão de obra terceirizada, os benefícios não foram verificados, sequer de modo indireto.

E, ainda, no estudo de Barth et al. (2016), analisou-se a influência da desoneração tributária no cálculo das tarifas de transportes intermunicipais, ao se avaliarem questões relativas ao equilíbrio econômico dos prestadores de serviços públicos. Os principais resultados da pesquisa apontam que houve redução no valor do coeficiente tarifário de todos os sistemas de transporte regulados pela agência e que os impactos da desoneração nos coeficientes tarifários giram em torno de 2,5\% a 4,5\%. Essa modificação afetou a estrutura das empresas ao influenciar no ponto de equilíbrio contábil e no giro de ativos.

Além desses autores que analisaram 0 impacto da desoneração no comportamento dos custos e resultados das empresas, outros autores, como Banker, Byzalov e Chen (2013) e Guenther, Riehl e Röbler (2014), argumentam que a legislação de proteção ao emprego interfere no comportamento dos custos. Nesta perspectiva, esta pesquisa caracteriza-se pela análise da forma como os custos se alteram em função de fatores e influências externas, que, neste estudo, é a desoneração previdenciária da folha de pagamento.

Portanto, com base nos argumentos e estudos anteriores apresentados, admitese, como hipótese de pesquisa, que o desempenho do segmento de calçados, observado por meio da ótica comportamental de custos, no período após a medida de desoneração, é estatisticamente diferente do observado no período anterior à desoneração. 
Observa-se o desempenho por meio das hipóteses de redução da média dos Gastos com Pessoal, Custo dos Produtos Vendidos, Despesas com Vendas e Administrativas e Custo Total em relação à Receita Líquida de Vendas. Além disso, o desempenho também é analisado por meio da hipótese de aumento da média do Lucro Líquido em relação à Receita Líquida de Vendas, conforme segue:

a) H1: A relação P/RLV, em média, diminui com a desoneração;

b) H2: A relação CPV/RLV, em média, diminui com a desoneração;

c) H3: A relação D/RLV, em média, diminui com a desoneração;

d) H4: A relação CT/RLV, em média, diminui com a desoneração;

e) H5: A relação LL/RLV, em média, aumenta com a desoneração.

Nota-se que o tema de estudo é atual e que as pesquisas nesta temática ainda podem se expandir, pois trata-se da introdução de um novo dispositivo legal que permite às empresas reduzirem os encargos trabalhistas. Então, conhecer os impactos dessa alteração nos custos e na carga tributária das empresas é oportuno e contribui para a literatura especializada.

Assim, a presente pesquisa busca investigar os custos de produção das empresas calçadistas, bem como os dispêndios com pessoal, despesas e margem de lucro, com o intuito de verificar possíveis alterações no comportamento destas variáveis após a desoneração da folha de pagamento.

\section{PROCEDIMENTOS METODOLÓGICOS}

A pesquisa foi realizada em empresas de capital aberto do segmento de calçados listadas na BM\&FBOVESPA, as quais foram verificadas no período de 2007 a 2016. Neste segmento, existem 5 empresas listadas; no entanto, destas analisaram-se as 3 empresas que divulgaram suas informações contábil-financeiras referentes ao período necessário às análises: Alpargatas S. A., Cambuci S. A. e Grendene S. A. Tais 
Desoneração previdenciária e o comportamento dos custos das empresas de calçados listadas na

BM\&FBOVESPA

Rúbia Albers Magalhães, Thayse Moraes Elias, Luiz Felipe Ferreira, Altair Borgert

empresas enquadram-se no setor Consumo Cíclico e subsetor Tecidos, Vestuário e Calçados.

A fim de detectar o comportamento das variáveis antes e após a desoneração, dividiu-se o período em dois momentos: um anterior e um posterior à medida. O período utilizado como anterior à desoneração refere-se ao 1ํㅡㄹ trimestre de 2007 ao $4^{\circ}$ trimestre de 2011. Embora a desoneração tenha iniciado em 01/12/2011, os meses de outubro e novembro desse ano, incluídos no trimestre, são anteriores à desoneração e mais representativos do que apenas o mês de dezembro. Portanto, o período considerado posterior à desoneração abrange do $1^{\circ}$ trimestre de 2012 ao $4^{\circ}$ trimestre de 2016.

Para realizar as análises, coletaram-se as informações trimestrais de Receita Líquida de Vendas - RLV; Custo dos Produtos Vendidos - CPV; Despesas de Vendas - DV; Despesas Administrativas - DA; e Lucro Líquido - LL, na base de dados Economática. Além destes dados, coletaram-se informações anuais de gastos com Pessoal - P, Receitas - R e Tributos Federais na Demonstração do Valor Adicionado DVA disponível no site da BM\&FBOVESPA. As análises que englobam as informações obtidas por meio da DVA abrangem o período de 2008 a 2016, em função do ano de obrigatoriedade dessa demonstração.

Após a coleta, exportaram-se os dados para o software MS Excel e, com auxílio de pacotes estatísticos, calculou-se a média da relação entre os gastos e as receitas das empresas antes e após a desoneração da folha de pagamento. Assim, obteve-se a análise do comportamento por meio dos Gastos com Pessoal/Receita (P/R), Custo dos Produtos Vendidos/Receita Líquida de Vendas (CPV/RLV), Despesas/Receita Líquida de Vendas (D/RLV), Custos Totais/Receita Líquida de Vendas (CT/RLV) e, por fim, Lucro Líquido/Receita Líquida de Vendas (LL/RLV). Para fins de análise, as despesas englobam as DV e DA, e os custos totais abrangem o CPV, DV e DA.

De posse das médias, primeiramente, verificou-se a estatística descritiva, para proporcionar evidências sobre a amostra. Posteriormente, elaborou-se a linha de tendência linear da média referente ao período anterior à desoneração e a linha de tendência linear referente ao período posterior à medida, a fim de identificar o 
comportamento dos gastos e da margem de lucro durante o período, que podem fornecer indícios de comportamentos tendenciosos das variáveis.

Por fim, as hipóteses foram testadas com o Teste t de Student em par para médias, na forma de duas médias para casa empresa, uma para o período anterior e uma para o período posterior à desoneração. Neste teste, as análises compreendem 15 conjuntos de dados, ao considerar 3 empresas e 5 variáveis de cada empresa. Vale destacar que esse teste não identifica o impacto direto da desoneração nas variáveis observadas, tão somente evidencia tendências dos custos, despesas e margem de lucro nos períodos anterior e posterior à desoneração, que podem ou não estar associadas a essa medida.

Ainda vale destacar que, por se tratar de um teste para amostras pareadas, as empresas devem apresentar média para ambos os períodos, anterior e posterior à medida. Assim, em função da disponibilidade de dados de 20 trimestres para o período posterior, foram coletados dados de 20 trimestres também para o período anterior, o que justifica o período de análise de 2007 a 2016, para obter médias com a mesma quantidade de observações, de forma a melhorar a comparabilidade.

Como pressuposto para o teste empregado, realizou-se o teste de Shapiro-Wilk a um nível de significância de $5 \%$ de todos os itens de gastos analisados, para cada empresa, o qual consiste em um teste de normalidade dos dados para averiguar a possibilidade de inferências estatísticas, comumente utilizado e adequado a amostras pequenas.

\section{APRESENTAÇÃO E ANÁLISE DE DADOS}

O objetivo desta pesquisa é verificar o impacto da medida governamental referente à desoneração da folha de pagamento nos gastos com pessoal, nos custos, nas despesas, bem como nos resultados das empresas do segmento de calçados listadas na BM\&FBOVESPA entre o período de 2007 a 2016. Analisam-se, então, dois momentos distintos: antes da desoneração e após a desoneração da folha de 
pagamento. Deste modo, comparam-se os dados dos períodos para identificar possíveis alterações nos gastos e resultados do segmento analisado.

Um fator relevante a ser considerado são os valores das receitas líquidas de vendas ao mercado externo. Esta situação resulta em alterações da base de cálculo da contribuição previdenciária, pois, conforme mencionado, a base de cálculo é a receita bruta, excluídas as receitas com exportação, entre outros itens. Verifica-se que as receitas com exportações das empresas Alpargatas, Cambuci e Grendene representaram, em média, $24 \%, 12 \%$ e $20 \%$, respectivamente, das receitas para o período analisado. Além disso, houve variabilidade neste percentual, que pode ter influenciado no valor do recolhimento da contribuição previdenciária.

Para ilustrar o possível impacto da desoneração da folha de pagamento, a Tabela 3 apresenta a representatividade dos tributos federais em relação aos gastos com pessoal durante todo o período analisado. Conforme mencionado, os dados coletados foram retirados da Demonstração do Valor Adicionado, que tem por finalidade evidenciar a riqueza criada pela empresa e sua distribuição, durante determinado período, conforme CPC 09 (Comitê de Pronunciamentos Contábeis, 2008). Assim, a riqueza distribuída ao Estado é composta por todos os tributos recolhidos aos governos.

Tabela 3

Percentual dos tributos federais sob os gastos com pessoal

\begin{tabular}{cccc}
\hline Período & Alpargatas & Cambuci & Grendene \\
\hline 2008 & $46,35 \%$ & $50,79 \%$ & $69,72 \%$ \\
2009 & $54,10 \%$ & $51,49 \%$ & $46,40 \%$ \\
2010 & $58,20 \%$ & $195,52 \%$ & $48,72 \%$ \\
2011 & $67,69 \%$ & $85,76 \%$ & $55,29 \%$ \\
2012 & $66,57 \%$ & $68,01 \%$ & $50,03 \%$ \\
2013 & $64,88 \%$ & $62,42 \%$ & $45,15 \%$ \\
2014 & $47,65 \%$ & $59,56 \%$ & $39,10 \%$ \\
2015 & $73,97 \%$ & $45,16 \%$ & $37,71 \%$ \\
2016 & $70,98 \%$ & $51,95 \%$ & $41,69 \%$ \\
\hline Antes & $56,59 \%$ & $95,89 \%$ & $55,03 \%$ \\
Após & $64,81 \%$ & $57,42 \%$ & $42,74 \%$ \\
\hline
\end{tabular}

Nota. Fonte: Elaborada pelos autores, com base nos dados da pesquisa 
Com base na Tabela 3, pode-se verificar que os tributos federais passaram a ter menor representatividade após o ano de 2011 em duas das três empresas, período em que o governo federal sancionou a desoneração no segmento analisado. Vale ressaltar que, nos tributos federais, além das contribuições para Previdência Social, estão incluídos todos os outros tributos devidos à União, os quais não têm relação com a desoneração da folha de pagamento. No entanto, há indícios de que a desoneração possa ter impactado no montante de tributos federais, ao considerar a queda da representatividade percentual.

Quanto às características gerais dos dados, apresenta-se a estatística descritiva na Tabela 4.

Tabela 4

\section{Estatística Descritiva}

\begin{tabular}{cccccc}
\hline Resumo estatístico & P/R & CPV/RLV & D/RLV & CT/RLV & LL/RLV \\
\hline Média & 0,1666 & 0,5775 & 0,3128 & 0,8903 & 0,1061 \\
Erro padrão & 0,0115 & 0,0053 & 0,0045 & 0,0074 & 0,0129 \\
Mediana & 0,1756 & 0,5818 & 0,3141 & 0,8931 & 0,1039 \\
Desvio padrão & 0,0344 & 0,0334 & 0,0286 & 0,0470 & 0,0814 \\
Variância da amostra & 0,0012 & 0,0011 & 0,0008 & 0,0022 & 0,0066 \\
Coeficiente de variação & 0,2062 & 0,0578 & 0,0914 & 0,0528 & 0,7677 \\
Mínimo & 0,0998 & 0,4554 & 0,2658 & 0,7227 & $-0,0156$ \\
Máximo & 0,2155 & 0,6328 & 0,3785 & 0,9645 & 0,4716 \\
Contagem & 9 & 40 & 40 & 40 & 40 \\
Maior & 0,2155 & 0,6328 & 0,3785 & 0,9645 & 0,4716 \\
Menor & 0,0998 & 0,4554 & 0,2658 & 0,7227 & $-0,0156$ \\
\hline
\end{tabular}

Nota. Fonte: Elaborada pelos autores, com base nos dados da pesquisa

Com base no coeficiente de variação, que representa um valor relativo da dispersão ou concentração dos dados em torno da média, pode-se perceber que os dados da relação $L L / R L V$ apresentam mais desvios da média do que a relação $P / R L V$, CPV/RLV, CT/RLV e D/RLV. Ou seja, as informações de margem de lucro são mais dispersas, e essa discrepância pode também ser observada nos valores mínimo (- 
0,0156) e máximo $(0,4716)$, enquanto os valores mínimos e máximos das demais variáveis são mais próximos uns dos outros.

Nas próximas etapas do estudo, analisa-se, por meio da linha de tendência e do Teste t de Student, a possível influência da desoneração no comportamento dos Gastos com Pessoal, dos Custos dos Produtos Vendidos, das Despesas, dos Custos Totais e da Margem de Lucro. Para a utilização do Teste t, os testes de normalidade ShapiroWilk evidenciaram distribuição normal dos dados para 11 dos 15 conjuntos de dados. Para os dados que não apresentaram distribuição normal com base nos testes, considera-se que a distribuição de probabilidade associada ao conjunto de dados é compatível com a distribuição normal em função da curva assintoticamente normal, de forma que mantém a validade dos resultados (Gujarati, 2006).

\section{a) Análise dos gastos com pessoal - P/R}

A análise dos gastos com pessoal identifica a tendência dos gastos com pessoal das empresas de calçados listadas na BM\&FBOVESPA durante o período anterior e posterior à desoneração da folha de pagamento, além de verificar se a média da relação P/RLV se alterou após a aplicação da medida.

Na Figura 1, apresenta-se a tendência da média da relação P/RLV de todas as empresas analisadas. Com base na Figura 1, é possível observar a tendência de aumento da relação $P / R L V$ durante o período anterior e posterior à desoneração da folha de pagamento. Dentre outras razões, este aumento pode ser explicado pelo aumento no quadro de funcionários que, consequentemente, implicou mais custos para as empresas analisadas. 
Desoneração previdenciária e o comportamento dos custos das empresas de calçados listadas na

BM\&FBOVESPA

Rúbia Albers Magalhães, Thayse Moraes Elias, Luiz Felipe Ferreira, Altair Borgert

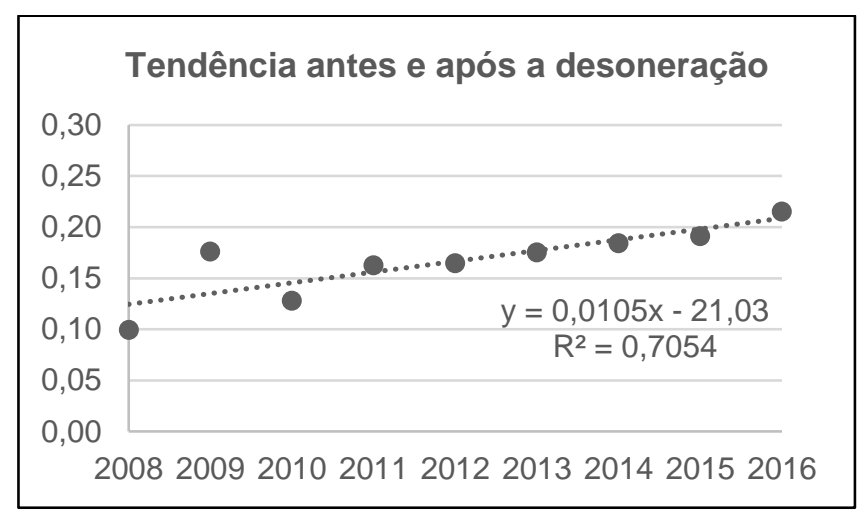

Figura 1. Comportamento dos gastos com pessoal

Fonte: Elaborada pelos autores, com base nos dados da pesquisa

Esses indícios são corroborados pelos dados setoriais divulgados pela Receita Federal, no qual afirma que a quantidade de vínculos deste segmento aumentou 22,62\% durante o período de 2012 a novembro de 2014 (Brasil, 2015c). No entanto, a fim de identificar se a média da relação P/RLV efetivamente se alterou após a desoneração da folha de pagamento, apresentam-se os resultados do Teste $t$ na Tabela 5.

Tabela 5

Teste t para a relação P/RLV

\begin{tabular}{lcc}
\hline \multicolumn{1}{c}{ Gastos com Pessoal/Receita } & Antes & Após \\
\hline Média & 0,1419 & 0,1863 \\
Variância & 0,0003 & 0,0005 \\
Observações & 3 & 3 \\
Correlação de Pearson & & 0,0079 \\
Hipótese da diferença de média & & 0 \\
gl & & 2 \\
Stat $t$ & & 2,6501 \\
$\mathrm{P}(T<=t)$ uni-caudal & 0,0589 \\
$\mathrm{t}$ crítico uni-caudal & & 2,9200 \\
\hline
\end{tabular}

Nota. Fonte: Elaborada pelos autores, com base nos dados da pesquisa

A partir dos resultados do teste apresentados na Tabela 5, é possível observar, ao nível de significância de 5\%, que os dados não fornecem evidência suficiente para 
Desoneração previdenciária e o comportamento dos custos das empresas de calçados listadas na

BM\&FBOVESPA

Rúbia Albers Magalhães, Thayse Moraes Elias, Luiz Felipe Ferreira, Altair Borgert

rejeitar a hipótese nula de que os gastos com pessoal não se alteraram com a medida, conforme a significância do teste de 0,0589. Nesse sentido, não se pode afirmar que há efetiva diferença nos gastos com pessoal entre os períodos analisados, ainda que a linha de tendência tenha evidenciado aumento na relação P/RLV após a desoneração da folha de pagamento.

\section{b) Análise dos custos dos produtos vendidos - CPV/RLV}

Nesta análise, identifica-se o comportamento dos custos dos produtos vendidos das empresas listadas no segmento de calçados da BM\&FBOVESPA. Apresenta-se, na Figura 2, a análise da tendência anterior ( $1^{\circ}$ ao $20^{\circ}$ trimestre) e posterior ( $21^{\circ}$ ao $40^{\circ}$ trimestre) à desoneração da folha de pagamento, de forma desassociada. Dessa forma, com as análises separadas, do período anterior e posterior ao evento, é possível compreender, com maior detalhamento, a tendência que os custos assumem nestes momentos.

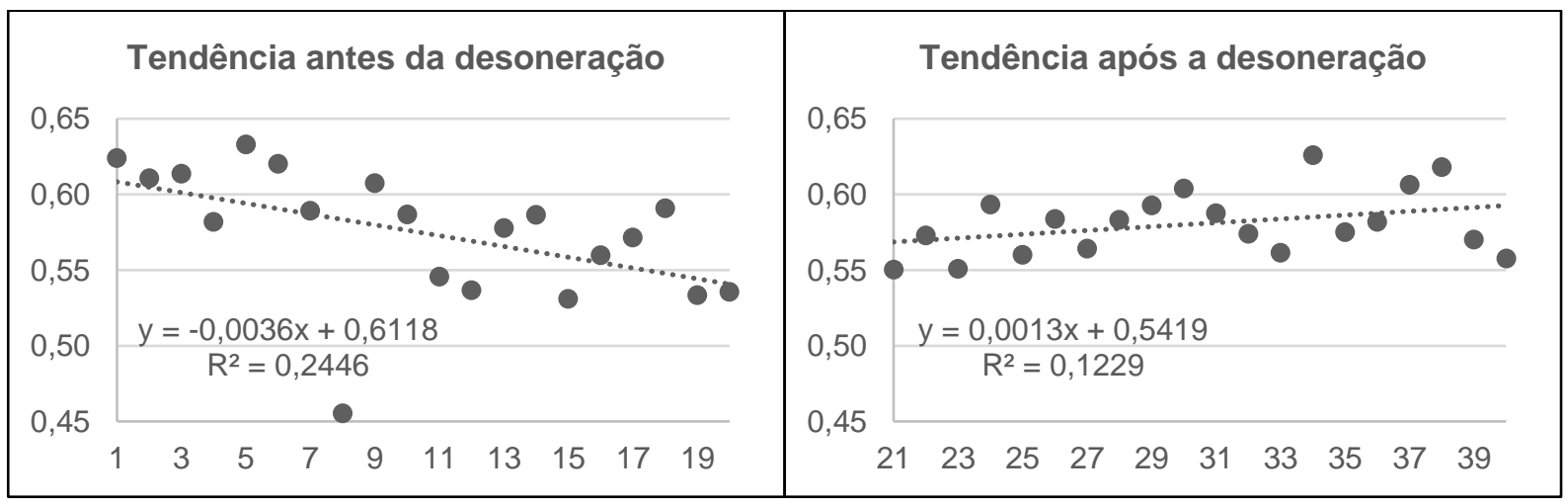

Figura 2. Comportamento dos custos dos produtos vendidos

Fonte: Elaborada pelos autores, com base nos dados da pesquisa

Verifica-se, com base nos gráficos elucidados, que o comportamento dos custos dos produtos vendidos apresenta uma tendência de queda antes da desoneração, devido ao coeficiente angular negativo. No entanto, no período após as iniciativas de desoneração, a tendência é de ascensão, representada pelo coeficiente angular positivo. Com base nestes dados, há indícios de que a desoneração não tenha 
impactado no comportamento dos custos dos produtos vendidos, uma vez que não houve redução no período analisado.

Com o intuito de examinar se houve efetivas diferenças de médias entre o período anterior e posterior à medida, que não sejam determinadas simplesmente pela aleatoriedade amostral, elabora-se o Teste t de Student, que tem por objetivo testar a hipótese de pesquisa de que os custos não apresentaram alterações com as medidas de desoneração, conforme Tabela 6 .

Tabela 6

Teste t para a relação CPV/RLV

\begin{tabular}{lcc}
\hline \multicolumn{1}{c}{ CPV/RLV } & Antes & Após \\
\hline Média & 0,5745 & 0,5806 \\
Variância & 0,0013 & 0,0011 \\
Observações & 3 & 3 \\
Correlação de Pearson & & 0,0978 \\
Hipótese da diferença de média & & 0 \\
gl & & 2 \\
Stat $t$ & & 0,2244 \\
$\mathrm{P}(\mathrm{T}<=\mathrm{t})$ uni-caudal & & 0,4216 \\
t crítico uni-caudal & & 2,9200 \\
\hline
\end{tabular}

Nota. Fonte: Elaborada pelos autores, com base nos dados da pesquisa

De acordo com a Tabela 6 , os dados, ao nível de significância de 5\%, não fornecem evidência suficiente para rejeitar a hipótese nula, como mostra a significância do teste de 0,4216, ou seja, não é possível afirmar que houve efetiva diferença nos custos entre os dois períodos analisados. Em outras palavras, o teste não sustenta a hipótese de que os custos dos produtos vendidos apresentaram alterações após a desoneração da folha de pagamento, o que permite inferir que a relação CPV/RLV não se modificou durante o período.

Um fator que pode interferir nestes resultados é a pouca representatividade dos gastos com mão de obra nos custos dos produtos, uma vez que gastos desta natureza podem estar inseridos de forma mais representativa nas despesas, conforme características da estrutura operacional da empresa. Assim, as alterações provenientes 
Desoneração previdenciária e o comportamento dos custos das empresas de calçados listadas na

BM\&FBOVESPA

Rúbia Albers Magalhães, Thayse Moraes Elias, Luiz Felipe Ferreira, Altair Borgert

da desoneração da folha de pagamento tornam-se menos evidentes no custo dos produtos, em função das classificações.

\section{c) Análise do comportamento das despesas - D/RLV}

Este tópico busca identificar o comportamento das despesas administrativas e despesas com vendas das empresas de calçados listadas na BM\&FBOVESPA. Da mesma forma que a análise anterior, apresenta-se, na Figura 3, a tendência anterior (1ํㅜ ao $20^{\circ}$ trimestre) e posterior $\left(21^{\circ}\right.$ ao $40^{\circ}$ trimestre) à desoneração da folha de pagamento, de forma desassociada.

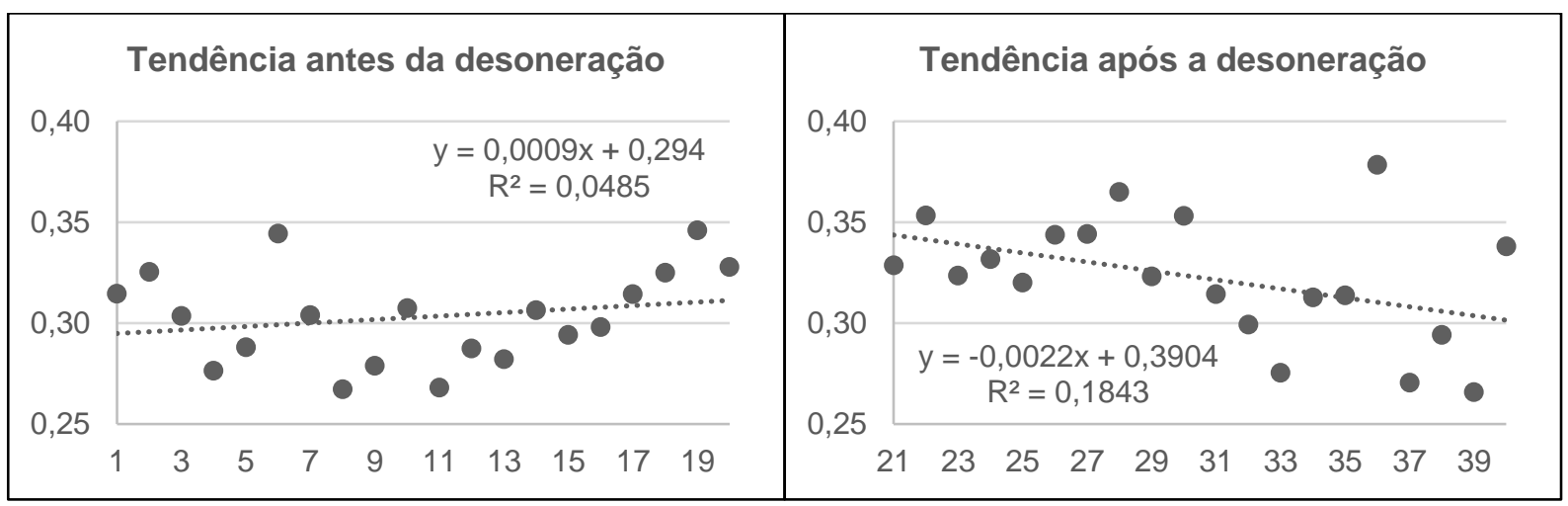

Figura 3. Comportamento das despesas

Fonte: Elaborada pelos autores, com base nos dados da pesquisa

Verifica-se, com base nos gráficos apresentados, que o comportamento das despesas com vendas e administrativas apresenta uma tendência de aumento antes da desoneração, devido ao coeficiente angular positivo. No entanto, no período posterior à desoneração, a tendência é de queda, conforme o coeficiente angular negativo.

Estes resultados podem estar associados à forma de classificação dos gastos com pessoal das empresas analisadas que, ao serem caracterizados como despesas, não são observados no comportamento dos custos, o que justifica as evidências de que os custos dos produtos vendidos das empresas analisadas não sofreram alterações.

Esta tendência, que caracteriza um aumento das despesas antes da desoneração e queda após a desoneração, pode estar relacionada a medidas da Lei 
Desoneração previdenciária e o comportamento dos custos das empresas de calçados listadas na

BM\&FBOVESPA

Rúbia Albers Magalhães, Thayse Moraes Elias, Luiz Felipe Ferreira, Altair Borgert

com relação à redução dos encargos e, consequentemente, redução dos gastos com mão de obra.

A fim de averiguar se as médias da relação D/RLV reduziram-se efetivamente, apresentam-se os resultados do Teste t na Tabela 7.

Tabela 7

Teste t para a relação D/RLV

\begin{tabular}{lcc}
\hline \multicolumn{1}{c}{ D/RLV } & Antes & Após \\
\hline Média & 0,3031 & 0,3226 \\
Variância & 0,0008 & 0,0060 \\
Observações & 3 & 3 \\
Correlação de Pearson & & 0,5660 \\
Hipótese da diferença de média & & 0 \\
gl & & 2 \\
Stat $t$ & & 0,5108 \\
$\mathrm{P}(T<=t)$ uni-caudal & & 0,3302 \\
$\mathrm{t}$ crítico uni-caudal & & 2,9200 \\
\hline
\end{tabular}

Nota. Fonte: Elaborada pelos autores, com base nos dados da pesquisa

Os resultados, ao nível de significância de 5\%, não fornecem evidência suficiente para rejeitar a hipótese nula, que afirma não haver diferença nas despesas entre o período anterior e posterior à desoneração, como mostra a significância do teste de 0,3302, ou seja, não é possível considerar que há diferença entre os dois períodos analisados. Em outras palavras, não se pode afirmar que houve efetiva redução na relação $D / R L V$ no período posterior à desoneração da folha de pagamento.

\section{d) Análise do comportamento dos custos totais - CT/RLV}

Este tópico identifica o comportamento do custo total das empresas (composto por CPV, DV e DA), para a compreensão dos efeitos da desoneração no âmbito operacional e administrativo.

Apresenta-se, portanto, a análise da tendência anterior ( $1^{\circ}$ ao $20^{\circ}$ trimestre) e posterior ( $21^{\text {a }}$ ao $40^{\circ}$ trimestre) à desoneração da folha de pagamento, separadamente, na Figura 4. Verifica-se, com base nos gráficos apresentados, que o comportamento 
dos custos totais apresenta uma tendência de queda antes da desoneração, bem como no período posterior à desoneração, devido ao coeficiente angular negativo.

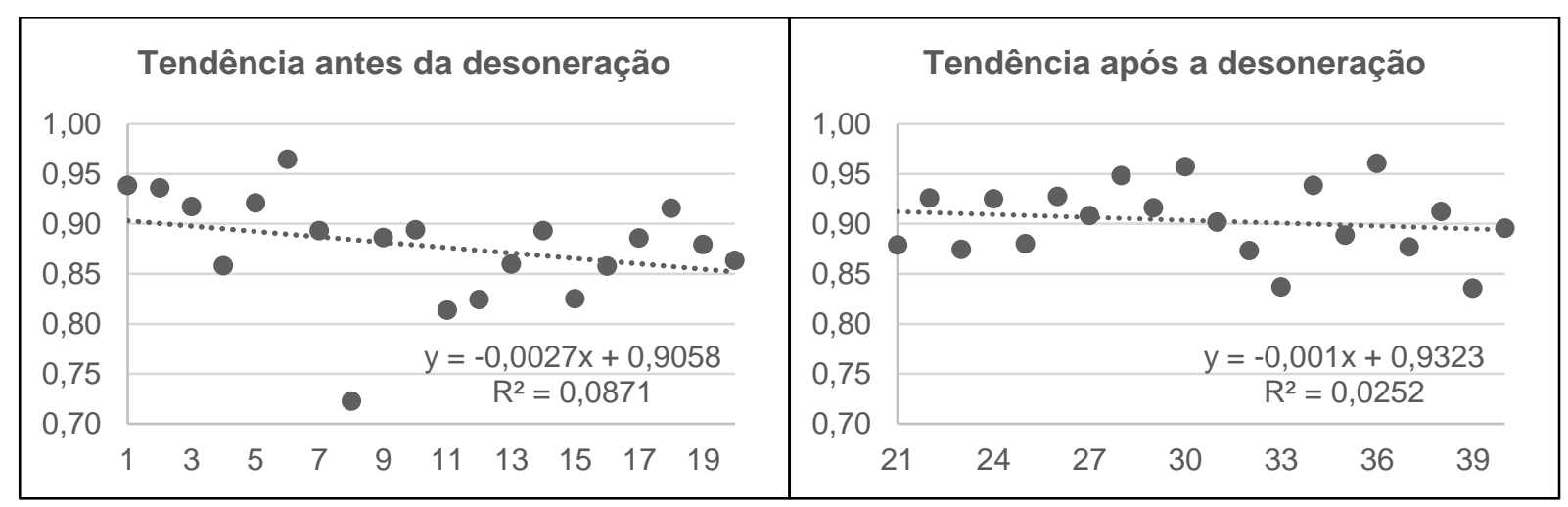

Figura 4. Comportamento dos custos totais

Fonte: Elaborada pelos autores, com base nos dados da pesquisa

Segundo levantamento dos dados para o período e empresas analisadas, o custo dos produtos vendidos representa cerca de $65 \%$ dos custos totais. Contudo, o custo dos produtos e as despesas apresentaram comportamentos inversos, o que explica o fato de os custos totais apresentarem comportamento praticamente linear, visualizado pelo baixo coeficiente angular, uma vez que as tendências dos gastos que 0 compõem tendem a se anular. Quanto ao Teste t, a Tabela 8 apresenta os resultados.

Tabela 8

Teste t para a relação $C T / R L V$

\begin{tabular}{lcc}
\hline \multicolumn{1}{c}{ CT/RLV } & Antes & Após \\
\hline Média & 0,8775 & 0,9031 \\
Variância & 0,0014 & 0,0116 \\
Observações & 3 & 3 \\
Correlação de Pearson & & 0,9454 \\
Hipótese da diferença de média & & 0 \\
Gl & & 2 \\
Stat $\mathrm{t}$ & & 0,6074 \\
$\mathrm{P}(\mathrm{T}<=\mathrm{t})$ uni-caudal & & 0,3027 \\
$\mathrm{t}$ crítico uni-caudal & & 2,9200 \\
\hline
\end{tabular}

Nota. Fonte: Elaborada pelos autores, com base nos dados da pesquisa. 
Os dados, ao nível de significância de 5\%, não fornecem evidência para rejeitar a hipótese nula, como mostra a significância do teste de 0,3027, ou seja, não se pode considerar que há diferença nos custos totais entre os dois períodos analisados. Este fato pode ser explicado ao se considerar que nos custos totais estão abrangidos os custos dos produtos vendidos, as despesas com vendas e as despesas administrativas que, de acordo com o Teste t, não sofreram alterações e, então, impactaram na análise conjunta.

Assim, de acordo com os resultados da Tabela 8, não é possível inferir que os custos totais das empresas do segmento de calçados, listadas na BM\&FBOVESPA, foram influenciados pela medida de desoneração da folha de pagamento, uma vez que, quando analisados individualmente e em conjunto, os custos dos produtos vendidos e as despesas com vendas e administrativas não apresentaram evidências de alterações com a medida, conforme o teste utilizado.

\section{e) Análise do comportamento da margem de lucro - LL/RLV}

Este último tópico de análise dos dados identifica o comportamento da margem de lucro das empresas de calçados listadas na BM\&FBOVESPA, de modo que se possa observar se a desoneração da folha de pagamento influenciou os resultados das empresas. Com o intuito de visualizar a tendência deste comportamento, apresenta-se a Figura 5. 
Desoneração previdenciária e o comportamento dos custos das empresas de calçados listadas na

BM\&FBOVESPA

Rúbia Albers Magalhães, Thayse Moraes Elias, Luiz Felipe Ferreira, Altair Borgert

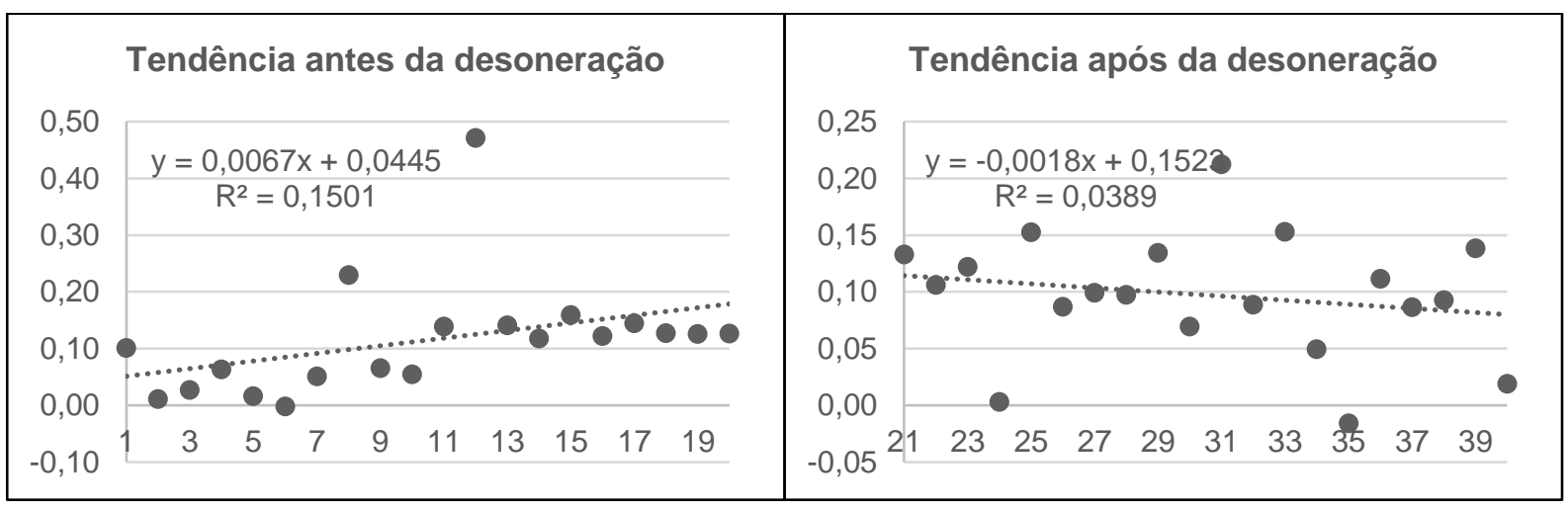

Figura 5. Comportamento da margem de lucro

Fonte: Elaborada pelos autores, com base nos dados da pesquisa

Verifica-se, com base nos gráficos apresentados, tendência de aumento no período anterior à desoneração, devido ao coeficiente angular positivo. No período posterior à desoneração, no entanto, a margem de lucro apresenta uma tendência de queda, evidenciada pelo coeficiente angular negativo.

O comportamento da margem de lucro pode ser justificado pela tendência inversa (queda antes da desoneração e aumento após a desoneração) do comportamento dos custos. Mas, a fim de tornar os dados analisados mais robustos e verificar se há efetiva diferença nas médias entre os dois períodos analisados, utiliza-se o Teste t, conforme a Tabela 9.

Tabela 9

Teste t para a relação LL/RLV

\begin{tabular}{lcc}
\hline \multicolumn{1}{c}{ LL/RLV } & Antes & Após \\
\hline Média & 0,1150 & 0,0971 \\
Variância & 0,0032 & 0,0247 \\
Observações & 3 & 3 \\
Correlação de Pearson & 0,9972 \\
Hipótese da diferença de média & 0 \\
gl & 2 \\
Stat t & $-0,3069$ \\
P(T<=t) uni-caudal & & 0,3940 \\
t crítico uni-caudal & & 2,9200 \\
\hline
\end{tabular}

Nota. Fonte: Elaborada pelos autores, com base nos dados da pesquisa 
Com base na Tabela 9, nota-se que os dados, ao nível de significância de 5\%, não apresentam evidência suficiente para rejeitar a hipótese nula, conforme a significância do teste de 0,3940. Nesse sentido, não se pode afirmar que há efetiva diferença na margem de lucro entre os dois períodos analisados, ainda que a linha de tendência tenha evidenciado queda na relação LL/RLV após a desoneração da folha de pagamento.

Este resultado pode ser explicado pela existência de outras variáveis, que podem intervir no resultado do segmento em análise e que não são exploradas, como, por exemplo, as despesas financeiras, que podem evidenciar aumentos no grau de endividamento, e as receitas com atividades não sujeitas à desoneração da folha de pagamento. Além disso, a elevada variância dos dados de LL/RLV em comparação aos dados de P/RLV, CPV/RLV, D/RLV e CT/RLV (conforme apresentado na Tabela 4) pode influenciar nos resultados.

\section{CONCLUSÕES}

Esta pesquisa buscou analisar o impacto da desoneração da folha de pagamento nos custos, nas despesas e na margem de lucro das empresas de calçados listadas na BM\&FBOVESPA, setor este que foi um dos primeiros inseridos na desoneração, a partir de 01/12/2011. Dessa forma, analisaram-se os gastos e a margem de lucro dessas empresas durante o período anterior e posterior à desoneração da folha de pagamento, isto é, analisou-se a forma como os custos se alteraram sob influências externas.

Inicialmente, verifica-se queda no percentual da relação entre os Tributos Federais e gastos com pessoal no período posterior à desoneração em duas das empresas analisadas, o que sugere que os montantes com tributos passaram a ter menor representatividade após a desoneração da folha de pagamento. No entanto, vale destacar que esta análise inclui outros tributos federais, que podem interferir nestes resultados e que não possuem relação com a Contribuição Previdenciária. 
Por meio da linha de tendência, pôde-se observar que os gastos com pessoal apresentaram tendência de aumento durante o período anterior e posterior à desoneração. Os custos dos produtos vendidos apresentaram tendência de queda antes da medida e tendência de aumento após a desoneração. As despesas, por sua vez, apresentaram tendência de aumento antes e tendência de queda após a desoneração, o que caracteriza uma possível melhora no desempenho das empresas analisadas. Com relação aos custos totais, apresentaram tendência de queda antes e após a desoneração da folha de pagamento. Por fim, a margem de lucro apresentou tendência de aumento antes e tendência de queda após a desoneração.

Os resultados do Teste $t$ encontrados apontam que os gastos com pessoal, os custos dos produtos vendidos e as despesas com vendas e administrativas não se alteraram com as medidas da desoneração, pois não encontrou-se evidência suficiente para rejeitar a hipótese nula. Assim, os custos totais, que abrangem os custos dos produtos vendidos e as despesas, também não foram impactados pela desoneração. Não obstante, nas análises da margem de lucro, não encontrou-se evidência suficiente para rejeitar a hipótese nula; portanto, conclui-se que a desoneração não interferiu nos resultados das empresas.

Nesse sentido, com base no teste de diferença de médias, os achados não correspondem às conclusões de outros estudos alinhados ao objetivo desta pesquisa, que tiveram como finalidade verificar o impacto da desoneração nos custos, despesas ou resultados das empresas, entreos quais podem-se mencionar Fregulia (2013), Eckert et al. (2013), Santos et al. (2013), Ferrari et al. (2014), Bertini e Wünsch (2014), Oliveira et al. (2014), Uszacki e Silva (2014), Echevarrieta et al. (2015), Ludwig et al. (2016) e Barth et al. (2016), que constataram alguma vantagem para as empresas analisadas, por meio das modificações na contribuição previdenciária, provenientes da medida de desoneração da folha de pagamento.

Esta pesquisa apresenta como limitação a impossibilidade de generalização dos resultados, por não analisar todas as empresas do segmento. Além disso, a análise dos dados não controla variáveis externas que podem influenciar nos achados. Assim, 
Desoneração previdenciária e o comportamento dos custos das empresas de calçados listadas na

BM\&FBOVESPA

Rúbia Albers Magalhães, Thayse Moraes Elias, Luiz Felipe Ferreira, Altair Borgert

sugere-se, para pesquisas futuras, a investigação em empresas de outros segmentos, bem como a inserção de variáveis como a quantidade de vínculos empregatícios, custos com salários e médias salariais, com o intuito de verificar os impactos da desoneração da folha de pagamento nos custos das empresas.

\section{REFERÊNCIAS}

Associação Brasileira das Indústrias de Calçados - ABICALÇADOS. (2016). A Abicalçados: perfil da indústria nacional. Novo Hamburgo, RS.

Banker, R. D., Byzalov, D., \& Chen, L. T. (2013). Employment protection legislation, adjustment costs and cross-country differences in cost behavior. Journal of Accounting and Economics, 55(1), 111-127.

Barth, V. S., Souza, A. R. L., \& Oliveira, L. (2016). Contabilidade tributária: Os efeitos da desoneração de contribuições previdenciárias sobre as tarifas de transporte intermunicipal de passageiros no Rio Grande do Sul. Contextus Revista Contemporânea de Economia e Gestão, 14(2).

Bertini, E. R., \& Wünsch, P. E. R. (2014). O impacto financeiro e contábil da desoneração da folha de pagamento em indústrias calçadistas do Vale do Paranhana. Revista Eletrônica do Curso de Ciências Contábeis, 3(1).

BM\&FBOVESPA - Bolsa de Valores. (2015).Mercadorias e Futuros. Recuperado de: http://www.bmfbovespa.com.br/CiasListadas/EmpresasListadas/BuscaEmpresaLista da.aspx?idioma=pt-br

Constituição da República Federativa do Brasil: Promulgada em 1988. Brasília: Senado.

Cintra, M. (2010). Movimentação financeira: a base de uma contribuição para o INSS em substituição à folha de pagamentos. Rev. adm. pública, 44(6),1477-1506.

Comitê de Pronunciamentos Contábeis. (2008). Pronunciamento Contábil CPC 09. Demonstração do Valor Adicionado. Recuperado de: http://static.cpc.mediagroup.com.br/Documentos/175_CPC_09.pdf

Crepaldi, S. A. (2012). Planejamento Tributário: teoria e prática. São Paulo: Saraiva.

Echevarrieta, A. C. C., Magalhães, R. A., Casagrande, M. D. H., \& Rosa, P. A. (2015). Desoneração da folha de pagamento: impactos fiscais e econômicos de um hotel em Florianópolis. Navus Revista de Gestão e Tecnologia, 5(2), 27-39. 
Eckert, A., Biasio, R., Mecca, M. S., \& Turella, O. (2013). Desoneração da folha de pagamento: impactos causados nos custos e nos preços de venda em uma indústria de vidros. Anais da Mostra de Iniciação Científica, Pós-Graduação, Pesquisa e Extensão, Caxias do Sul, RS, Brasil, 13.

Ferrari, M. J., Kremer, A. W., \& Silva, M. C. (2014). Desoneração da folha de pagamento e comportamento dos custos das empresas de fios e tecidos do estado de Santa Catarina listadas na BM\&FBOVESPA. Anais do Congresso Brasileiro de Custos, Natal, RN, Brasil, 21.

Fregulia, B. T. (2013). Desoneração da folha de pagamento: um estudo de caso em uma empresa do setor de construção civil da região da AMESC-SC (Trabalho de Conclusão de Curso). Universidade do Extremo Sul Catarinense - UNESC, Santa Catarina, SC, Brasil.

Guenther, T. W., Riehl, A., \& Röbler, R. (2014). Cost stickiness: state of the art of research and implications. Journal of Management Control, 24(4), 301-318.

Gujarati, D. (2006). Econometria básica (4a. ed.). Rio de Janeiro: Elsevier.

Instituto Brasileiro de Planejamento Tributário - IBPT. (2015). Carga tributária avança para 35,42\% do PIB em 2014, aponta IBPT. Recuperado de: https://www.ibpt.org.br/noticia/2144/carga-tributaria-avanca-para-35-42-do-pib-em2014-aponta-ibpt

Instrução Normativa RFB no 971, de 13 de novembro de 2009. Diário Oficial [da] República Federativa do Brasil. Recuperado de: http://normas.receita.fazenda.gov.br/sijut2consulta/link.action?idAto=15937\&. Brasil. (2009).

Lei no 8.212, de 24 de Julho de 1991. Diário Oficial [da] República Federativa do Brasil. Brasília: Poder Executivo, Brasil. (1991).

Lei no 12.546, de 14 de dezembro de 2011.Diário Oficial [da] República Federativa do Brasil. Brasília: Poder Executivo, Brasil. (2011a).

Lei no 13.161, de 31 de agosto de 2015.Diário Oficial [da] República Federativa do Brasil. Brasília: Poder Executivo, Brasil. (2015a).

Ludwig, M. J., Borgert, A., \& Kremer, A. W. (2016). Desoneração da folha de pagamento e comportamento dos custos em empresas de construção civil. Pensar Contábil, 18(66), 14-23.

Medida Provisória n. 540, de 02 de agosto de 2011.Diário Oficial [da] República Federativa do Brasil. Brasília: Poder Executivo, Brasil. (2011b). 
Desoneração previdenciária e o comportamento dos custos das empresas de calçados listadas na

BM\&FBOVESPA

Rúbia Albers Magalhães, Thayse Moraes Elias, Luiz Felipe Ferreira, Altair Borgert

Ministério da Fazenda. (2012). Desoneração da Folha de Pagamentos. Brasil. (2015b). Recuperado de: http://www1.fazenda.gov.br/portugues/documentos/2012/cartilhadesoneracao.pdf.

Neves Jr, I. J. N., Fernandes, C. M., \& Barreto, M. D. (2016). Perícia Contábil sobre a desoneração da folha de pagamento: Caso em empresa de construção de obras de infraestrutura. Pensar Contábil, 18(66), 36-49.

Oliveira, A. M. B., Petri, S. M., Casagrande, M. D. H., \& Rosa, P. A. (2014). O impacto da mudança de base de cálculo e alíquota da contribuição previdenciária patronal em empresas do setor moveleiro. Revista da UNIFEBE, 1(14),35-48.

Plano Brasil Maior. (2011). Plano Brasil maior: Inovar para competir. Competir para crescer. Recuperado de: http://www.brasilmaior.mdic.gov.br/conteudo/128

Santos, D. S., Freitas, P. J. M., Tomasi, S. L., Pietrobelli, V., \& Dutra, C. C. (2013). Os impactos financeiros da lei 12.546/2011 em empresas do segmento plástico. Anais do Seminário de Iniciação Científica de Ciências Contábeis, Caxias do Sul, RS, Brasil, 7, p. 506-520.

Secretaria da Receita Federal. Desoneração da Folha de Pagamento. Relatório das Desonerações. Desoneração da Folha de Pagamento: estimativa de renúncia e metodologia de cálculo. Brasil. (2015c). Recuperado de: http://idg.receita.fazenda.gov.br/dados/receitadata/gastos-tributarios/renuncia-fiscalsetorial

Secretaria da Receita Federal. Desoneração da Folha de Pagamento - Análise e Modelo Alternativo. Brasil. (2015). Recuperado de: https://idg.receita.fazenda.gov.br/dados/receitadata/estudos-e-tributarios-eaduaneiros/trabalhos-academicos/desoneracao-da-folha-de-pagamentos-analise-emodelo-alternativo.pdf.

Secretaria da Receita Federal. Histórico - Previdência Social. Brasil. (2016). Recuperado de: http://www.previdencia.gov.br/acesso-ainformacao/institucional/historico/

Uszacki, A., \& Silva, A. S. (2014). A desoneração da folha de pagamento: estudo de caso na empresa metalúrgica Aço e Silva Ltda. Gestão Contemporânea: Revista de Negócios do Cesuca, 1(2),62-88.

Data de Submissão: 11/08/2016

Data de Aceite: 29/05/2017 